\title{
USG Guided Combined Spinal Epidural: A Boon in an Achondroplasic Dwarf undergoing an Orthopaedic Procedure
}

\section{Divyadarshni Vadivel* and Deepa Kane}

Department of Anesthesiology, King Edward Memorial Hospital, Mumbai, Maharashtra, India

\begin{abstract}
Achondroplasia is one of the commonest forms of dwarfism. A 26-year-old achondroplasic dwarf with vitamin $D$ deficiency was posted for an elective shaft of femur fixation. Owing to her difficult airway and past history of tuberculosis, it was decided upon to operate her under combined spinal and epidural anaesthesia. This case report highlights on the need for real time ultrasound guidance in locating the epidural space and hence aiding in successful placement of the Quincke's needle and the epidural catheter. The ultrasound is an effective and reliable tool to ascertain the most feasible inter-vertebral space in cases of a difficult spine anatomy.
\end{abstract}

Keywords: Achondroplasia; Ultrasound; Difficult spinal

\section{Introduction}

Achondroplasia is an autosomal dominant disorder caused by sporadic mutation of the FGFR 3 gene leading to abnormal enchorial ossification. It is characterized by disproportionate dwarfism, a relatively large head, midfacial hypoplasia, deformations of the spine, leg axis deviation, spinal canal stenosis, kyphoscoliosis, reduced epidural space and vertebral body deformities posing a challenge to both region and general anaesthesia [1]. Anaesthetic management of achondroplastic patients undergoing a variety of elective and emergency surgical procedures have been reported, the most common include limb lengthening surgeries [2], Caesarean section [3], bariatric surgery [4], laparotomy for bilateral oophorectomy [5], vascular repairs [6] and middle ear surgeries [7]. Neuraxial block can be a challenge and hence the use of real time ultrasound could mitigate unsuccessful epidural insertions.

\section{Case Report}

A 26-year-old female presented with a fracture of the right femur for which a femur fixation was planned. She was a known case of achondroplasia and vitamin D deficiency, chronically immobile with a history of fall leading to pain and swelling of her hip. She was an old case of pulmonary tuberculosis for which she was adequately treated. On physical examination she was measured to be $118 \mathrm{~cm}$ with a weight of 40 $\mathrm{kg}$. She had a large head disproportionate to her body with short neck, mandibular protrusion and a kyphoscoliotic spine. Airway examination showed an MPC III, restricted neck movements, a thyromental distance of $5 \mathrm{~cm}$ and adequate mouth opening. Cardiovascular system examination was normal with a heart rate of $68 / \mathrm{min}$ and a blood pressure of $110 / 70$ $\mathrm{mm}$ of Hg. Respiratory system examination revealed a depressed chest wall with a protuberant abdomen and thoracic kyphosis, auscultation of the chest was unremarkable. An endocrine opinion was taken in view of vitamin D deficiency ( $\downarrow$ vitamin $\mathrm{D}, \uparrow \mathrm{PTH}$ ) and optimization of vitamin $\mathrm{D}$ and calcium were done prior surgery. Cardiac and pulmonary medicine work up was also done. Her biochemical profile and blood profile were within permissible limits with the exception of her hemoglobin being $9.3 \mathrm{~g} \%$. Electrocardiogram showed bilateral ventricular hypertrophy which was ensued by $2 \mathrm{D}$ echo wherein the ejection fraction was $60 \%$. Arterial blood gas analysis showed a $\mathrm{PH}-7.42, \mathrm{PCO}_{2}-37, \mathrm{PaO}_{2}-108$ and saturation of $98 \%$ on room air. Central neuraxial block was planned on this patient in view of anticipated difficult intubation and previous history of pulmonary tuberculosis. The patient was explained the procedure of a combined spinal epidural and the chances of a multiple/ failed attempts and the need for conversion to general anesthesia. Standard anesthesia care of electrocardiogram, pulse oximetry, $\mathrm{ETCO}_{2}$ and noninvasive blood pressure were used to monitor the patient Intravenous access was obtained on the right upper limb using a 20G IV cannula. The patient was preloaded with $250 \mathrm{~mL}$ of ringer's lactate. The patient was given a left lateral position. Ultrasound was used to identify the intervertebral space and hence the spaces for epidural catheter placement and subarachnoid block. The best space for epidural and the distance to reach the epidural space was calculated.

Epidural space was obtained at L1 L2 intervertebral space and the catheter was fixed at $6 \mathrm{~cm}$. Spinal was given at the $\mathrm{L} 3 \mathrm{~L} 4$ intervertebral space. $2 \mathrm{cc}$ of $0.5 \%$ bupivacaine heavy was injected using a $25 \mathrm{~g}$ Quincke's needle. Post subarachnoid block the patient was given head high to prevent high spinal levels. Despite head high a pre-operative spinal level of T6 was obtained. The procedure lasted for $3 \frac{1}{2}$ hours. Epidural was activated using $2 \mathrm{~mL}$ of $2 \%$ preservative free lignocaine and thereafter an infusion of $3 \mathrm{cc}$ of $0.375 \%$ bupivacaine was started. Patient was hemodynamically stable throughout the procedure. Blood loss of around $350 \mathrm{~mL}$ occurred during the procedure and was replaced. Post procedure spinal level was L1 and the patient was comfortable and pain free. The epidural catheter was removed post operatively as the aim of our epidural was only to prolong the duration of anaesthesia (Figure 1).

\section{Discussion}

Achondroplasia also known as short limb dwarfism has an incidence of 1 to $1.5 / 10000$ live births [8]. It is inherited in an autosomal dominant fashion with the incidence being higher amongst females. Spontaneous mutation of the FGFR 3 gene leads to enchondral ossification of the epiphyseal growth plate [8,9]. An achondroplasic patient can pose significant challenges to the anaesthesiologist. Hence preoperative assessment and planning of anaesthesia are of foremost concerns. Routine biochemical profile, lung functions, echocardiograph and ABG analysis have to be sought for in relevant cases [10]. It is prudent to ask for a neurological consult in cases with cervicomedullary stenosis and

*Corresponding author: Divyadarshni Vadivel, Department of Anesthesiology, King Edward Memorial Hospital, Mumbai, Maharashtra, India, Tel: 0222410 7000; E-mail: divyadarshniv@kem.edu

Received September 14, 2017; Accepted January 18, 2018; Published January 23, 2018

Citation: Vadivel D, Kane D (2018) USG Guided Combined Spinal Epidural: A Boon in an Achondroplasic Dwarf undergoing an Orthopaedic Procedure. J Clin Case Rep 8: 1077. doi: 10.4172/2165-7920.10001077

Copyright: $\odot 2018$ Vadivel D, et al. This is an open-access article distributed under the terms of the Creative Commons Attribution License, which permits unrestricted use, distribution, and reproduction in any medium, provided the original author and source are credited. 


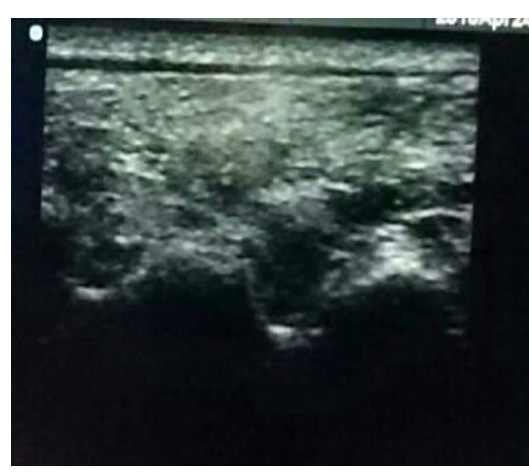

Figure 1: Ultrasound image.

cervical canal stenosis. General anaesthesia can be a challenge to the anesthetist owing to difficult mask ventilation, difficult intubation with regards to relatively larger heads, midfacial hypoplasia, restricted neck movements, cervicomedullary stenosis and cervical canal stenosis [11]. Regional anaesthesia in dwarfs could be complicated by the presence of ill-defined anatomical landmarks, spinal stenosis, osteophytes, short pedicles or a small epidural space. This could lead to multiple attempts at getting to the epidural space, increased risk of dura puncture, erratic spread of the local anesthetic and patchy action owing to the smaller space and stenosed canal. A number of authors and studies have warranted the use of general anesthesia owing to its safety profile, but we opted for a combined spinal epidural owing to our patient's difficult airway and past history of pulmonary tuberculosis. Different methods have evolved over the years to ease in identification of the intervertebral spaces like $\mathrm{X}$ ray of the spine. MRI and ultrasonography over the conventional landmark technique when encountered with a difficult spine. Each method has its limitations owing to non-feasibility in the operating room. Real time ultrasonography was found to be an easy, readily available technique in locating the most suitable intervertebral disc, the depth of insertion and the direction of Insertion of the Tuohy's and Quincke's needle [11,12]. Given the difficult anatomy in this patient we have justified the use of the ultrasound in identifying the appropriate space thereby alleviating agony to the patient in terms of multiple attempts and long durations of induction.

\section{Conclusion}

A case of successful spinal and epidural anesthesia in an achondroplasic dwarf using ultrasonography to identify the space followed by loss of resistance technique to reach the epidural space for an orthopedic procedure has been described. The use of real time ultrasonography in attempting central neuraxial block in cases wherein difficulty arises with the use of the traditional landmark technique is highly recommended.

\section{References}

1. JainA, Jain K, Makkar JK, Mangal K(2010)Case study:Anaesthetic management of an achondroplastic dwarf undergoing radical nephrectomy. Southern Afr J Anaesth Analg 16: 77-79.

2. Brimacombe JR, Goddard JM (1993) Leg lengthening in children-a retrospective review of anaesthetic management in 61 children including 14 with achondroplasia. Pediatr Anesth 3: 89-93.

3. Brimacombe JR, Caunt JA (1990) Anaesthesia in a gravid achondroplastic dwarf. Anaesth 45: 132-134.

4. Nandini MD, Santhosh EM, Sushma W (2006) Combined spinal epidural anaesthesia for removal of bilateral ovarian masses by laparotomy in a patient with proportionate dwarfism. Indian J Anaesth 50: 304-7.

5. Abrão MA, Silveira VGD, Barcellos CFLVD, Cosenza RCM, Carneiro JRI, et al. (2009) Anestesia em anã acondroplásica obesa mórbida para gastroplastia redutora. Rev Bras Anestesiol 59: 79-86.

6. Al-Jughiman M, Yanagawa B, Rondi K, Dalamagas C, Peterson MD, et al. (2014) Acute type A dissection repair in an achondroplastic dwarf: Anesthetic, perfusion, and surgical concerns. AORTA 2: 143.

7. Krishnan BS, Eipe N, Korula G (2003) Anaesthetic management of a patient with achondroplasia. Pediatr Anesth 13: 547-549.

8. Orioli IM, Castilla EE, Barbosa-Neto JG (1986) The birth prevalence rates for the skeletal dysplasias. J Med Genet 23: 328-332.

9. Vajo Z, Francomano CA, Wilkin DJ (2000) The molecular and genetic basis of fibroblast growth factor receptor 3 disorders: the achondroplasia family of skeletal dysplasias, Muenke craniosynostosis, and Crouzon syndrome with acanthosis nigricans 1. Endocrine Rev 21: 23-39.

10. Berkowitz ID, Raja SN, Bender KS, Kopits SE (1990) Dwarfs: pathophysiology and anesthetic implications. Anesthesiol 73: 739-759.

11. Karmakar MK, Li X, Ho AH, Kwok WH, Chui PT (2009) Real-time ultrasoundguided paramedian epidural access: evaluation of a novel in-plane technique. Brit J Anaesth 102: 845-854.

12. Tran D, Kamani AA, Al-Attas E, Lessoway VA, Massey S, et al. (2010) Singleoperator real-time ultrasound-guidance to aim and insert a lumbar epidural needle. Canadian J Anesth 57: 313-321. 